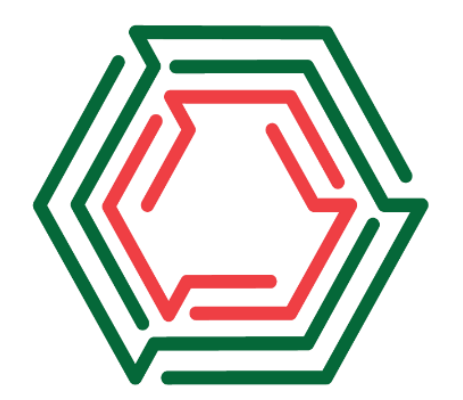

IV Congresso Internacional das Licenciaturas COINTER - PDVL 2017

\title{
NÚMEROS PRIMOS: UMA PROPOSTA DE APLICAÇÃO ATRAVÉS DO CRIVO DE SUNDARAM
}

Apresentação: Comunicação Oral

Priscila Maia Veras Freitas ${ }^{1}$; Camyla Aragão de Moura $^{2}$; Jeane Gardênia Costa do Nascimento ${ }^{3}$

\begin{abstract}
Resumo
A matemática desde a antiguidade sempre se fez presente em nosso cotidiano firmando-se na sociedade principalmente devido ao avanço científico e tecnológico uma vez que a mesma é aplicável nas mais diversas áreas. Essa diversidade de aplicações conduz o trabalho docente a adaptações que permitam a melhor apropriação pelos estudantes dos conteúdos abordados o que está diretamente ligado a metodologias de ensino, nesse sentido, o presente trabalho é resultado de pesquisa realizada durante o estágio supervisionado ocorrido na Unidade Escolar Cristino Castelo Branco, em Teresina (PI) com vinte e três estudantes do $2^{\circ}$ ano do Ensino Médio sobre o tema Números Primos. Durante a pesquisa de embasamento teórico, essa aplicação em especial conhecida como o Crivo de Sundaram mostrou-se como uma ferramenta bastante interessante e oportuna para identificação de números primos a ser utilizada com estudantes do ensino médio, visto que a mesma utiliza conceitos abordados nesse nível da educação básica. Objetivando analisar a influência da utilização do Crivo como ferramenta não convencional para a identificação de Números Primos dentro do contexto de aprendizagem que envolveu conteúdos já trabalhados em sala de aula, foi elaborada e aplicada uma atividade de cunho prático norteada por levantamento bibliográfico e investigação a cerca das dificuldades apresentadas pelos estudantes sobre o tema. Os resultados apontam que os estudantes sentiram-se mais motivados a participar e aprender quando recursos diversificados são apresentados como forma de incrementar conteúdos previstos no programa didático sem perder o foco da aula tradicional, sempre aproveitando o que já foi abordado. Professora titular da turma e os estudantes concordaram que a atividade investigativa foi bastante prazerosa e significativa, visto que a mesma possibilitou o engajamento e consequentemente a melhor compreensão do tema.
\end{abstract}

Palavras-Chave: Números Primos, Crivo de Sundaram, Metodologia de Ensino, Motivação.

\section{Introdução}

A matemática, enquanto ciência faz-se presente desde a antiguidade na sociedade humana firmando-se basicamente por conta dos avanços científico e tecnológico, tendo aplicações nas mais diversas áreas. Tal multiplicidade é fator primordial e motivador para o professor apresenta-la aos

\footnotetext{
${ }^{1}$ Pós-graduanda em Ensino de Matemática, IFPI Teresina Central, priscila.maia.30@hotmail.com

${ }^{2}$ Pós-graduanda em Ensino de Matemática, IFPI Teresina Central, camyla.aragao.moura@hotmail.com

${ }^{3}$ Mestre em Ensino de Ciências e Matemática, Professora IFPI Teresina Central, jeane.gardenia@ifpi.edu.br
} 
estudantes com vistas a despertar curiosidade e encanto da disciplina, tornando o seu estudo prazeroso e fomentando a qualidade do Ensino Básico.

Motivada por essa problemática e buscando identificar maneiras de diminuir as dificuldades já percebidas no processo de ensino e aprendizagem de Matemática na educação básica, faz-se necessário que o trabalho do professor esteja apoiado na utilização dos mais diversos recursos disponíveis para que os estudantes possam compreender a importância e aplicabilidade no cotidiano do que lhes é apresentado.

Dificuldades nos processos aritméticos básicos como adição, subtração, multiplicação, divisão e potenciação estão presentes durante as atividades propostas em sala de aula, assim como em procedimentos algébricos, os quais necessitam dos conceitos um pouco mais avançados para sua construção e desenvolvimento. Essa dificuldade é encontrada não somente nos estudantes das séries iniciais da educação básica, mas também nos cursos de graduação.

Nesse contexto, estratégias de ensino devem ter como objetivo maior, potencializar o processo de ensino e aprendizagem de conteúdos, em especial aqueles que servirão de base para toda a trajetória escolar.

\section{- Números Primos}

Diante dessa realidade, o presente artigo descreve a trajetória de elaboração e aplicação de uma atividade prática sobre o tema Números Primos, atividade esta, embasada por estudos bibliográficos em literatura pertinente, vale ressaltar que a escolha do tema foi determinada pelo fato de este estar presente na vida escolar desde a base que envolve a utilização de seu conceito primário, até o abstrato como, por exemplo, as criptografias utilizadas em dados bancários sendo essa talvez a sua mais importante aplicação tecnológica na atualidade, além dos inúmeros desafios que despertam a curiosidade estudantil.

Suas particularidades vêm ao longo dos tempos intrigando pesquisadores e sendo objeto de longos estudos. Dentro da educação básica, a importância desses números passa quase que despercebida e eis que surge o questionamento: Como podemos trabalhar esses números no atual currículo escolar? Buscando a resposta, foram realizadas pesquisas junto a referências específicas possibilitando identificar detalhes e curiosidades sobre esses números tão especiais que serviram de base para a elaboração de uma atividade que visou apresentar de maneira diferenciada uma forma encontrar números primos, e para verificar sua eficácia, tal atividade foi aplicada em uma turma do segundo ano do Ensino Médio de uma escola da rede pública de Teresina.

Durante a pesquisa de embasamento teórico, uma aplicação em especial conhecida como o Crivo de Sundaram mostrou-se como uma ferramenta bastante interessante e oportuna para identificação de números primos a ser utilizada com estudantes do ensino médio, visto que a mesma 
utiliza conceitos abordados nesse nível da educação básica. Os crivos, segundo Fonseca, 2014, p. 22, são, essencialmente, geradores de números primos. Cada um tem sua importância de acordo com sua simplicidade, velocidade e implementação computacional.

$\mathrm{O}$ autor ainda destaca que o Crivo de Sundaram baseia-se numa matriz formada a partir de números em progressões aritméticas (P.A.). Em outras palavras, sequências de números que encontram-se a uma determinada distância fixa, chamada de razão da P.A.

Por exemplo, tome-se a sequência infinita em que os números da sucessão formam uma P.A. de razão $r_{1}=3$ e primeiro termo $a_{1}=4: 4,7,10,13,16,19,22,25, \ldots$

Em seguida, uma segunda P.A. de razão $r_{2}=2+r_{1}=5$, cujo primeiro termo é o segundo termo $a_{2}=7$ da primeira P.A., isto é, $7,12,17,22,27,32,37,42, \ldots$

Agora, uma terceira P.A. de razão $r_{3}=2+r_{2}=7$, cujo primeiro termo é o terceiro termo $a_{3}=10$ da primeira P.A., ou seja, 10, 17, 24, 31, 38, 45, 52, 59, ..

Percebendo-se o padrão emergente: Cada linha $i$ tem como primeiro termo o termo $a_{i}$ da primeira P.A. e a razão de uma P.A. na linha $i$ e dada por $3+2(i-1)$.

Escrevendo as sequências aritméticas uma abaixo da outra, na forma de uma matriz infinita S, tem-se como mostra a tabela abaixo a seguinte configuração:

Suas particularidades vêm ao longo dos tempos intrigando pesquisadores e sendo objeto de longos estudos. Dentro da educação básica, a importância desses números passa quase que despercebida e eis que surge o questionamento: Como podemos trabalhar esses números no atual currículo escolar? Buscando a resposta, foram realizadas pesquisas junto a referências específicas possibilitando identificar detalhes e curiosidades sobre esses números tão especiais que serviram de base para a elaboração de uma atividade que visou apresentar de maneira diferenciada uma forma encontrar números primos, e para verificar sua eficácia, tal atividade foi aplicada em uma turma do segundo ano do Ensino Médio de uma escola da rede pública de Teresina.

Durante a pesquisa de embasamento teórico, uma aplicação em especial conhecida como o Crivo de Sundaram mostrou-se como uma ferramenta bastante interessante e oportuna para identificação de números primos a ser utilizada com estudantes do ensino médio, visto que a mesma utiliza conceitos abordados nesse nível da educação básica. Os crivos, segundo Fonseca, 2014, p. 22, são, essencialmente, geradores de números primos. Cada um tem sua importância de acordo com sua simplicidade, velocidade e implementação computacional. 
O autor ainda destaca que o Crivo de Sundaram baseia-se numa matriz formada a partir de números em progressões aritméticas (P.A.). Em outras palavras, sequências de números que encontram-se a uma determinada distância fixa, chamada de razão da P.A.

Por exemplo, tome-se a sequência infinita em que os números da sucessão formam uma P.A. de razão $r_{1}=3$ e primeiro termo $a_{1}=4: 4,7,10,13,16,19,22,25, \ldots$

Em seguida, uma segunda P.A. de razão $r_{2}=2+r_{1}=5$, cujo primeiro termo é o segundo termo $a_{2}=7$ da primeira P.A., isto é, $7,12,17,22,27,32,37,42, \ldots$

Agora, uma terceira P.A. de razão $r_{3}=2+r_{2}=7$, cujo primeiro termo é o terceiro termo $a_{3}=10$ da primeira P.A., ou seja, 10, 17, 24, 31, 38, 45, 52, 59, ..

Percebendo-se o padrão emergente: Cada linha $i$ tem como primeiro termo o termo $a_{i}$ da primeira P.A. e a razão de uma P.A. na linha $i$ e dada por $3+2(i-1)$.

Escrevendo as sequências aritméticas uma abaixo da outra, na forma de uma matriz infinita S, tem-se como mostra a tabela abaixo a seguinte configuração:

Tabela 1: Crivo de Sundaram (Fonte: autoria própria)

$\begin{array}{rrrrrrrrr}4 & 7 & 10 & 13 & 16 & 19 & 22 & 25 & 28 \\ 7 & 12 & 17 & 22 & 27 & 32 & 37 & 42 & 47 \\ 10 & 17 & 24 & 31 & 38 & 45 & 52 & 59 & 66 \\ 13 & 22 & 31 & 40 & 49 & 58 & 67 & 76 & 85 \\ 16 & 27 & 38 & 49 & 60 & 71 & 82 & 93 & 104 \\ 19 & 32 & 45 & 58 & 71 & 84 & 97 & 110 & 123 \\ 22 & 37 & 52 & 67 & 82 & 97 & 112 & 127 & 142 \ldots\end{array}$

A matriz apresenta a seguinte estrutura: a primeira linha é igual à primeira coluna, a segunda linha é igual a segunda coluna, a terceira linha é igual a terceira coluna e assim sucessivamente, cada linha é uma progressão aritmética, com as razões das progressões consecutivas formando a sequência $3,5,7,9,11,13,15,17, \ldots$, que também é uma P.A. de razão 2. Podendo concluir, também, que a matriz é simétrica.

Em seguida, escolhe-se qualquer número nesta matriz, multiplica-se por 2 e adiciona-se 1, verificando se o número resultante é primo. Na verdade, repetindo o procedimento algumas vezes, será possível constatar que, não importa o número eleito dentro da matriz, este jamais será um número primo.

O que poderia ser dito em relação aos números que não estão na matriz, por exemplo, 5, 6 e 8 ? Para um número $q$ não pertencente à, o número $2 q+1$ é primo. 
Desta forma, de acordo com o Crivo de Sundaram, é possível afirmar:

- Se q encontra-se na matriz $\mathrm{S}$, então $2 q+1$ não é primo;

- Se q não se encontra na matriz S, então $2 q+1$ é primo.

Podem-se resumir essas duas proposições em uma só: $2 q+1$ é primo, se e somente se, $q$ não está na matriz S. Conforme a demonstração:

Pode-se começar determinando uma fórmula de entrada na matriz $\mathrm{S}$. O primeiro termo na $\mathrm{n}$ ésima linha é $4+3(n-1)=3 n+1$. A diferença comum na progressão aritmética compreendida na $n$ ésima linha é $2 n+1$; assim, o m-ésimo número na n-ésima coluna é $3 n+1+(m-1)(2 n+1)=(2 m+1) n+m$.

Então, se $q$ aparece na matriz S, $q=(2 m+1) n+m$ para algum par de inteiros $m$ e $n$. Assim, $2 q+1=2(2 m+1) n+2 m+1=(2 m+1)(2 n+1)$ é composto. Mostra-se, agora, que, se $q$ não aparece na matriz $\mathrm{S}$, então $2 q+1$ é primo, ou de modo equivalente, se $2 q+1$ não é primo, então $c$ aparece na matriz. Suponha-se que $2 q+1=a . b$, onde $a, b$ são inteiros maiores que 1 .

Uma vez que $2 q+1$ é ímpar, $a$ e $b$ devem ser ímpares também, logo $a=2 p+1$ e $b=2 t+1$.

Assim,

$$
2 q+1=a \cdot b=(2 p+1)(2 t+1)=2 p(2 t+1)+2 t+1
$$

$\mathrm{e}$

$$
q=(2 t+1) p+t .
$$

Isso significa que $q$ é o t-ésimo número da $p$-ésima linha na matriz $\mathrm{S}$.

Conclui-se que $2 q+1$ é um número primo se, e somente se, $q$ não aparece na matriz S.

Ainda de acordo com FONSECA (2014, p. 26), é possível construir uma tabela com o Teste de Primalidade de Sundaram, sendo possível que concluir se o número é, ou não, primo. O crivo de Sundaram estabelece que se um número $q$ estiver na matriz de Sundaram, então $2 q+1$ não é primo, mas se $q$ não aparece na matriz, então $2 q+1$ é primo. Consideremos a situação contrária. Vamos analisar se um número $p$ é ou não primo, tentando determinar se $q=\frac{(p-1)}{2}$ está ou não na matriz.

Como exemplo, queremos verificar se 2573 é primo pelo crivo de Sundaram.

De acordo com as informações já obtidas, 2573 será primo se na matriz de Sundaram, não existir nenhum número $q$, tal que $2 q+1=2573$, vemos que para essa equação $q=1286$ não deve 
estar na matriz e também não devem existir $m$ e $n$ inteiros positivos tais que $(2 m+1)(2 n+1)=2573$, que indicaria uma linha e uma coluna onde $q$ se encontraria.

$$
\begin{gathered}
(2 m+1)(2 n+1)=2573 \\
4 m n+2 m+2 n+1=2573 \\
4 m n+2 m+2 n+1=2572 \\
2(2 m n+m+n)=2572 \\
2 m n+m+n=1286
\end{gathered}
$$

\begin{tabular}{|c|c|c|c|}
\hline $\mathrm{m}$ & $2 m+1$ & $\frac{p}{2 m+1}=2 n+1$ & $\mathrm{n}$ \\
\hline 1 & 3 & $\frac{2573}{3}=857,666 \ldots$ & $428,333 \ldots$ \\
\hline 2 & 5 & $\frac{2573}{5}=514,6$ & 256,8 \\
\hline 3 & 7 & $\frac{2573}{7}=367,571 \ldots$ & $183,286 \ldots$ \\
\hline 4 & 9 & $\frac{2573}{9}=285,888 \ldots$ & $142,444 \ldots$ \\
\hline 5 & 11 & $\frac{2573}{11}=233,909 \ldots$ & $116,455 \ldots$ \\
\hline 6 & 13 & $\frac{2573}{13}=197,923 \ldots$ & $98,4615 \ldots$ \\
\hline 7 & 15 & $\frac{2573}{15}=171,533 \ldots$ & $85,2667 \ldots$ \\
\hline 8 & 17 & $\frac{2573}{17}=151,353 \ldots$ & $75,1765 \ldots$ \\
\hline 9 & 19 & $\frac{2573}{19}=135,421 \ldots$ & $67,2105 \ldots$ \\
\hline 10 & 21 & $\frac{2573}{21}=122,524 \ldots$ & $60,7619 \ldots$ \\
\hline 11 & 23 & $\frac{2573}{23}=111,87 \ldots$ & $55,4348 \ldots$ \\
\hline
\end{tabular}

Se existirem tais valores de $m>0$ e $n>0$, eles são menores que $q$. testando vários valores de $m$, obtêm-se os seguintes valores de $n$ dados na tabela abaixo:

Tabela 2: Teste de Primalidade (Fonte: autoria própria) 


\begin{tabular}{|c|c|c|c|}
\hline 12 & 25 & $\frac{2573}{25}=102,92$ & 50,96 \\
\hline 13 & 27 & $\frac{2573}{27}=95,2963 \ldots$ & $47,1481 \ldots$ \\
\hline 14 & 29 & $\frac{2573}{29}=88,7241 \ldots$ & $43,8621 \ldots$ \\
\hline 15 & 31 & $\frac{2573}{31}=83$ & 41 \\
\hline
\end{tabular}

Como $m=15$ e $n=41$ satisfazem a equação $(2 m+1)(2 n+1)=2573, \operatorname{logo} q=1286$ aparece na matriz de Sundaram, estando o mesmo na linha 15 e coluna 41. Por conseguinte, 2573 não é primo.

\section{Fundamentação Teórica}

De acordo com Lima (2006, p.11),

"A aquisição de conceitos matemáticos nas primeiras séries é suporte não só para o decorrer da vida escolar, mas também para o cotidiano dos educandos. Por estar tão presente no dia-a-dia, estes conceitos devem ser bem trabalhados e desenvolvidos ao longo do processo. O papel do professor nesse período é de encaminhar os alunos para uma melhor compreensão desses conceitos, desafiando-os a encontrar soluções para questões que enfrentam na vida diária".

A realidade escolar, no entanto, aponta para um avanço dos estudantes nas séries iniciais sem, contudo, haver a devida apropriação de conceitos elementares em todas as disciplinas e a Matemática não foge a essa situação. Em sala de aula é comum encontrar estudantes desmotivados e em muitos casos sem perspectivas e expectativas sobre ensino, muitos inclusive, têm a Matemática como disciplina totalmente desvinculada do seu cotidiano. Segundo Rangel (1992, p.17)

"O ensino de matemática nas séries iniciais não leva em conta suas experiências diárias, nas quais estabelece relações de semelhanças e diferenças entre objetos e fatos, classificando-os, ordenando-os e quantificando-os. Assim, o ensino torna-se distante da realidade, a criança é induzida a aceitar uma situação artificial, sem significado para ela."

Com essa afirmação, autor reforça a ideia da necessidade de articulação entre o que se aprende e o cotidiano fazendo com que os estudantes consigam visualizar a pertinência do que é exposto pelo professor e a importância dessa articulação para a qualidade de sua aprendizagem.

Para reforçar tais ideias, de acordo com os $\operatorname{PCN}(1997$, p.25): 
"Os alunos trazem para a escola conhecimentos, ideias e intuições, construídos através das experiências que vivenciam em seu grupo sociocultural. Eles chegam à sala de aula com diferenciadas ferramentas básicas para, por exemplo, classificar, ordenar, quantificar e medir. Além disso, aprendem a atuar de acordo com os recursos, dependências e restrições de seu meio.”.

Sobre esses números especiais Ribenboim, já no prefácio de seu livro intitulado Números Primos: Velhos Mistérios e Novos Recordes afirma que:

Um número primo é um número inteiro maior que 1, que só admite como divisores ele próprio e 1. Os demais inteiros maiores que 1,não-primos são chamados compostos. Todo número composto é produto de números primos. A menos pela ordem dos fatores, esse produto é único. Esse é o teorema fundamental da aritmética. Então, os números primos formam blocos de base para a construção dos números inteiros, por meio da operação de multiplicação.

A afirmação do autor nos permite concluir que números primos são a base fundamental para todos demais números estudados durante a educação básica. Seu conceito inicial, embora simples, possibilita diversas aplicações.

\section{Metodologia}

Para a execução do projeto de pesquisa foram realizados, estudos bibliográficos em livros didáticos do Ensino Médio bem como de literatura específica sobre o tema Números Primos, visando comparar e catalogar definições, conceitos, métodos de reconhecimento e demonstrações que embasaram a elaboração da atividade a ser proposta em sala de aula.

De cunho qualitativo, a pesquisa utilizou-se do ambiente natural como fonte direta de coleta de dados, teve a pesquisadora como instrumento fundamental para esta coleta e além disso foram realizadas descrições havendo a preocupação essencial com o significado que os sujeitos investigados deram ao experimento e tais características casam perfeitamente com o que Ludke e André (2012, p. 11-13) pontuam como pesquisa qualitativa.

O ambiente escolhido para sua realização foi Unidade Escolar Cristino Castelo Branco, localizada na zona norte de Teresina (PI) e o sujeitos investigados pertenciam a uma turma de vinte e três estudantes do $2^{\circ}$ ano do Ensino Médio, a duração da atividade foi de seis tempos de cinquenta 50 minutos cada um.

O primeiro momento, com duração de dois tempos, foi de embasamento e recapitulação do conceito de Números Primos e do conteúdo Progressões Aritméticas, durante essa fase foi possível identificar fragilidades na aprendizagem dos estudantes.

Após o estudo inicial, em outro dia da semana, passou-se a explicações necessárias para a construção da matriz que representa o Crivo de Sundaram utilizando o conceito de P.A, foram 
utilizados dessa vez, quatro tempos, nesse momento foi possível verificar grande participação dos estudantes na atividade proposta, essa construção despertou a curiosidade dos envolvidos e os mesmos perceberam que alguns números estavam ausentes da tabela formada. Após algumas discussões chegou-se a conclusão que alguns dos números ausentes tinham características de Números Primos. Os estudantes foram instigados a participar através de questionamentos sobre o conteúdo, o que possibilitou melhor compreensão do tema abordado.

Essa participação deu-se principalmente com idas voluntárias ao quadro (tabela 3) e resolução de testes individuais e coletivos nos cadernos. Uma das propostas que mais chamou a atenção da turma foi fazer o teste de primalidade, que causou curiosidade e empolgação por parte dos estudantes que iam ao quadro, mostravam os cadernos e faziam seus cálculos tentando obter a resposta. Eles passaram a fazer suas tabelas com os números expostos no quadro, mas também arriscavam testes com outros números que gostariam de saber se eram ou não primos, como por exemplo, o número 4189.

Ao final, foi aplicado um pequeno questionário (Apêndice A) para identificar se houve ou não aprendizagem além dos aspectos positivos e/ou negativos a respeito da metodologia proposta.

Tabela 3: Participação da turma na construção do Crivo de Sundaram.
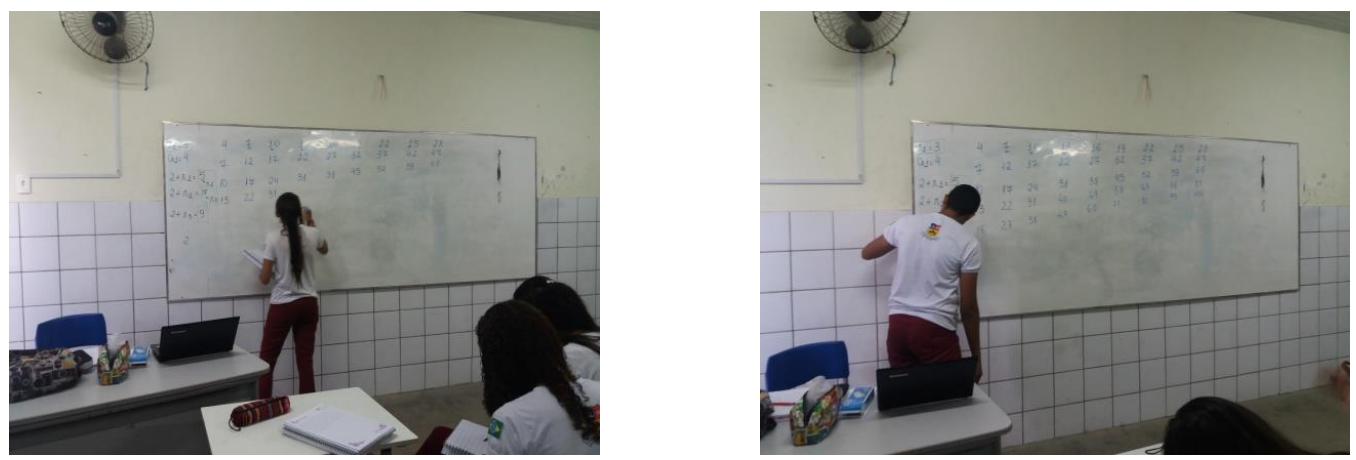

De acordo com os PCN (1997, p.29), é necessário contribuir para o desenvolvimento cognitivo do aluno, permitindo que ele aumente sua capacidade de compreender e resolver atividades mais complexas, o que fica claro na afirmação:

"As necessidades cotidianas fazem com que os alunos desenvolvam uma inteligência essencialmente prática, que permite reconhecer problemas, buscar e selecionar informações, tomar decisões e, portanto, desenvolver uma ampla capacidade para lidar com a atividade matemática. Quando essa capacidade é potencializada pela escola, a aprendizagem apresenta melhor resultado. (...) É fundamental não subestimar a capacidade dos alunos, reconhecendo que resolvem problemas, mesmo que razoavelmente complexos, lançando mão de seus conhecimentos sobre o assunto e buscando estabelecer relações entre o já conhecido e o novo." 


\section{Resultados e Discussão}

O resultado foi bastante positivo e produtivo, a turma participou efetivamente, colaborando uns com os outros em um trabalhou conjunto. A maioria dos estudantes obteve um conhecimento mais significativo e foi possível observar, através do gráfico 1, uma maior compreensão sobre o tema proposto, compreensão esta não obtida apenas com aula expositiva.

Gráfico 1. Fonte Própria.

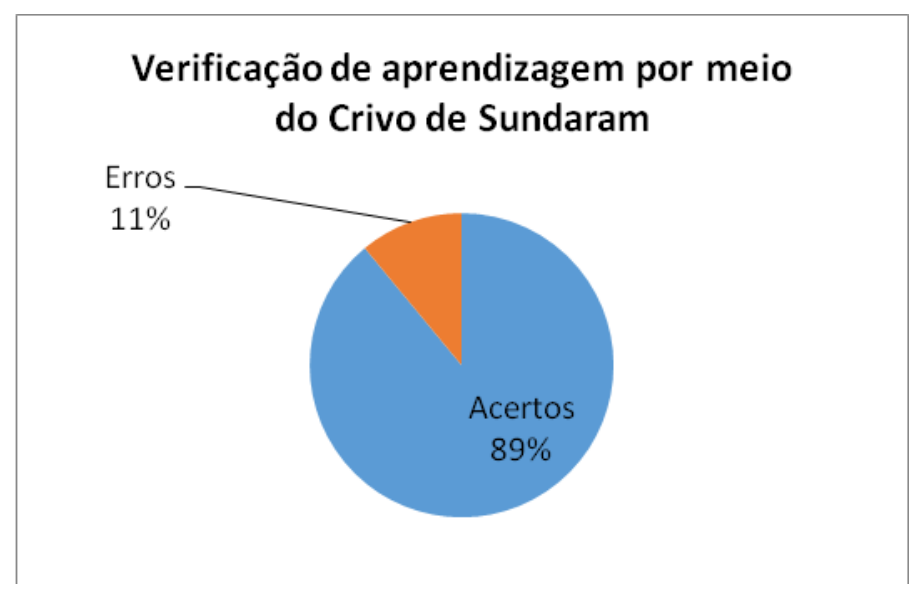

Os estudantes mostram-se muito empolgados com a dinâmica da aula, pois, além da compreensão, existiu interação entre toda a turma, fato não ocorrido em oportunidades anteriores. Foi possível trabalhar o conteúdo de forma coerente com o nível de ensino, permitindo que os estudantes aprimorassem o conhecimento anterior.

Fiorentini e Miorin (1990, p.3) afirmam:

"Ao aluno deve ser dado o direito de aprender. Não um "aprender" mecânico, repetitivo, de fazer sem saber o que faz e porque faz. Muito menos um "aprender" que se esvazia em brincadeiras. Mas um aprender significativo, do qual o aluno participe raciocinando, compreendendo, reelaborando o saber historicamente produzido e superando, assim, sua visão ingênua, fragmentada e parcial da realidade.".

Os depoimentos de alguns estudantes e da professora titular da turma ilustram o clima de satisfação gerado pela aula. Três estudantes afirmaram:

E1 - “A matemática é uma disciplina muito difícil e pouco aceitável por todos nós. Essa foi a melhor aula que já vi, jamais pensei aprender algo diferenciado como hoje. Nós nos divertimos e ficamos surpresos com mistérios que não conhecíamos. Foi bem melhor para quebrar o gelo em sala de aula durante uma atividade comum. Espero que tenhamos muitas vezes aulas parecidas com essa. E claro que depois desse dia as progressões e números primos não serão mais tão complicados".

E2 - "Eu tenho muita dificuldade em matemática. Meus professores não eram muito ativos, e apesar de não ter conseguido compreender tudo que foi exposto, gostei da iniciativa, da forma 
como trabalhamos juntos. Talvez se a professora continuar com isso, eu consiga melhorar. Hoje pareceu que a professora e nós éramos um só, cada um se ajudando.".

Já o depoimento da professora titular afirmou que: “O novo recurso foi muito importante para o aprendizado de todos. Temos poucos professores que se arrisquem a tal atividade, as chances deles são reduzidas com o descaso da educação, e quando alguém que está prestes a ser um professor chega e apresenta uma nova perspectiva, a visão deles fica mais ampla e abrangente. Sem dúvidas eles serão outros alunos depois dessa aula, jamais tinha visto tanta interação e trabalho em equipe.".

Uma dos focos da atividade era realmente fazer com que os estudantes se sentissem motivados, alguns não conseguiram compreender todo o conteúdo, mas se esforçaram e ficaram estimulados a continuar buscando novas ferramentas de aprendizagem.

É oportuno salientar que a questão quatro do (apêndice A) foi uma das questões mais discutidas e onde foi possível verificar com maior intensidade do trabalho em conjunto e dos questionamentos acerca de dúvidas, levando-lhes ao resultado final esperado.

\section{Conclusões}

O estudo empreendido permite concluir que o trabalho docente realizado através de pesquisas bibliográficas associadas a atividades de cunho experimental, possibilita aos estudantes uma melhor compreensão dos conteúdos propostos em sala de aula, uma vez que os mesmos avaliam e associam o que está sendo estudado a conhecimentos previamente adquiridos, o que torna a aula mais atrativa e significativa potencializando a apreensão de novos conteúdos.

Para o docente, fica a comprovação de aspectos sempre destacados na literatura sobre o uso de recursos didáticos em sala de aula, motivam os estudantes e fomentam a aprendizagem o que consequentemente também o motiva e o incentiva à elaboração de novas atividades.

É importante destacar também a não obrigatoriedade e nem a necessidade atividades muito rebuscadas e uso de materiais que demandam grandes quantias e sim que, recursos simples bem trabalhados podem fazer diferença no aprendizado da Matemática.

\section{Referências}

BRASIL, Secretaria de Educação Fundamental. Parâmetros Curriculares Nacionais: matemática. Brasília: MEC, SEF, 1997.

FIORENTINI, D.; MIORIN, M. A.. Uma reflexão sobre o uso de materiais concretos e jogos no ensino de matemática. Boletim da Sociedade Brasileira de Educação Matemática. São Paulo: SBEM-SP, n.7, p. 1-3, 1990. 
FONSECA, Rubens Vilhena. Percursos investigativos para o trabalho com números primos: uma proposta com o emprego de crivos de primalidade. UEPA 2014. Pg: 22 a 27.

FREIRE, Benedito Tadeu Vasconcelos. Notas de Aula Teoria dos Números. 2009, p. 22 a 24.

HEFEZ, Abramo. Elementos de Aritmética. $2^{\text {a }}$ Ed. Coleção do Professor de Matemática. Rio de Janeiro: SBM, 2011. 176p. ISBN 9788585818258

LANDAU, Edmund. Teoria Elementar dos Números. Rio de Janeiro: Ciência Moderna, 2002. 296p. ISBN 8573931744

LUDKE, Menga; ANDRÉ, Marli. Pesquisa em Educação: abordagens qualitativas. (Reimpressão). São Paulo: EPU, 2012.

LIMA, Cristiane Scheffer da Silveira de. As dificuldades encontradas por professores no ensino de conceitos matemáticos nas séries iniciais. Universidade Do Extremo Sul Catarinense UNESC. Criciúma, dezembro 2006.

OLIVEIRA, Krerley Irraciel Martins e FERNANDES, Adan José Corcho. Iniciação à Matemática: Um Curso com Problemas e Soluções. $1^{\mathrm{a}}$. Ed. Coleção Olimpíadas de Matemática. Rio de Janeiro: SBM, 2010. 283p. ISBN 9788585818463.

RANGEL, Ana S. Educação matemática e a construção do número pela criança. Porto Alegre: Artes Médicas, 1992.

RIBENBOIM, Paulo. Números Primos: Velhos mistérios e novos recordes. Rio de Janeiro: IMPA, 2012.

SHOKRANIAN, Salahoddin. Uma Introdução à Teoria dos Números. $1^{\text {a }}$ Ed. Rio de Janeiro: Ciência Moderna, 2008. 248p. ISBN 857393753X

APÊNDICE A (Questionário Após utilizar o Crivo de Sundaram):

Prof: Priscila Maia Véras Freitas

Aplicação: Números Primos: Uma Proposta de Aplicação através do Crivo de Sundaram

1) Diga, se justificando, se os números 42,187 e 211 são primos.

2) Identifique qual dos seguintes inteiros é primo:

$\begin{array}{llll}\text { a) } 91 & \text { b) } 191 & \text { c) } 791 & \text { d) } 771\end{array}$

3) Responda as seguintes perguntas:

a) Qual é o menor inteiro positivo, maior do que 1, que divide 4189 ?

b) Qual é o menor inteiro positivo, maior do que 1, que divide 2627 ?

4) Pelo teste de primalidade, verifique se 2456 e 1765 são primos

5) Você considera importante que os professores utilizem recursos diversificados na sala de aula?

6) O que achou da aula e da nova proposta através do Crivo de Sundaram? 